\title{
O desenvolvimento de competências em atenção básica à saúde: a experiência no projeto Huka-Katu
}

\author{
The development of competences on primary health care: \\ experience in the Huka-Katu project
}

Wilson M estriner Júnior ${ }^{1}$

Soraya Fernandes M estriner $^{1}$

AlexandreFávero Bulgarelli ${ }^{2}$

Silvana $\mathrm{M}$ artins $\mathrm{M}$ ishima ${ }^{2}$

${ }^{1}$ Universidade de São

Paulo, Faculdadede

Odontologia de Ribeirão

Preto, Departamento de

Clínica Infantil e

Odontologia Preventiva e

Sanitária. Av. do Cafés/n,

MonteAlegre.

14040-904 Ribeirão Preto

SP. mestri@forp.usp.br

${ }^{2}$ Escola deEnfermagem de

Ribeirão Preto,

Universidadede São Paulo.
Abstract This article explores the possibility of integration in the learning process in health services network of the $\mathrm{N}$ ative People $\mathrm{H}$ ealth Subsystem, an integrant part of the Brazilian Unified $\mathrm{H}$ ealth System. This leading role is present in several instances and stimulates changes in the health professional education. It also emphasizes that the pedagogical conception and the methodologies of the teaching-learning process are important themes for the devel opment of competencies of new health professionals. The aim of this article is to present by means of a descriptiveanalysis, the context in which the preparatory process is developed for the optative stage "H ukaKatu project - FORP-USP in the Xingu" highlighting the development of cognitive aspects presented in the proposition of actions directed to the primary care. The required competencies for the practice of the surgeon dentist in the primary health careis the base for the construction of SUS, while these competencies should answer the needs for the articulation of practice and education in a perspective of health care.

Key words Dental education, Dental health education, H uman resources formation, Professi onal competence, Primary health care
Resumo 0 artigo explora a possibilidade de integração no processo de aprendizagem à rede de serviços de saúde do subsistema de saúde indígena integrante do Sistema Ú nico de Saúde e colabora com o processo de formação profissional na área da saúde. Enfatiza também quea concepção pedagógica e as metodologias de ensino-aprendizagem são temas importantes para o desenvolvimento das competências dos novos profissionais da saúde. Com isto, o objetivo desteartigo éapresentar, através da análise descritiva, o contexto em que se de senvolve o processo preparatório para o estágio optativo "Projeto Huka-Katu - a FORP-USP no Xingu", ressaltando os aspectos cognitivos presentes na proposi ção de ações voltadas para a atenção primária. Considera-se ainda que as competências requeridas para o trabal ho do cirurgião-dentista na atenção básica à saúde se constituem em um suporte (base) para a construção do SUS, sendo que estas competências devem atender as necessidades de articulação da prática e da educação, em uma perspectiva do cuidado à saúde.

Palavras-chave Educação em odontologia, Educação em saúde bucal, Formação de recursos humanos, Competência profissional, Atenção básica à saúde 
O processo de ensino-aprendizagem em saúde

Ao longo da história, a educação na área da saúde seguiu diferentes lógicas e estratégias educacionais, sendo que a mais utilizada baseava-se em regulamentar, enquadrar e controlar todos os gestos e atitudes comportamentais, hábitos e discursos das classes subalternas, destruindo ou apropriando-se do modo e uso do "saber", definido pelas classes dominantes: do corpo, da saúde, da doença. Tais estratégias estavam correlacionadas com o esforço generalizado de moralização e domestificação das classes populares.

Para tanto, a relação entre professor e estudante, na instituição de ensino ou fora dela, enfatizava a transmissão do conteúdo. A atitude muitas vezes autoritária do professor como aquele detentor do saber e do poder fazia com que fosse "depositado" este conteúdo no estudante, que 0 absorvia sem questioná-lo, apenas arquivandoo. Por isso, esta pedagogia de transmissão (educação bancária) apresenta-se, ainda hoje, como domestificadora e alienante'.

Esta visão da educação considera o indivíduo como ser de adaptação e ajustamento. N os cursos de odontologia, a separação de disciplinas clínicas, teóricas e humanas gera consequências se melhantes e desencadeia um processo de dessensibilização progressiva dos estudantes da área da saúde². Cabe ressaltar que esta é uma situação presente nas diferentes profissões da área da saúde, sustentada por uma concepção que permeia a formação na área desde 0 início do século $X X$, tendo por base as recomendações do Relatório Flexner, com repercussões presentes ainda hoje $\mathrm{e}^{3}$.

N esta virada de século, tem-se colocado como um dos desafios para as instituições formadoras, órgãos governamentais e para a sociedade como um todo a revisão da forma como se organizam o ensino, a pesquisa e a articulação com os serviços de saúde na universidade brasileira, que tem sofrido críticas no sentido de se colocar distante de atender às necessidades sociais prioritárias, terminando por reforçar os padrões da prática odontológica vigente restritiva. Esta prática faz emergir efeitos deletérios, sobretudo da naturalização da perda dentária e da ênfase ao "protetismo" 4 .

Este ensaio reconhece como importantes tais críticas e o desafio colocado e, ao mesmo tempo, aponta como necessária a reflexão acerca da potência das premissas e pressupostos da já reconhecida educação problematizadora freiriana, que se fundamenta na criatividade e estímulo à ação e à reflexão sobre a realidade, bem como à busca pela capacidade de solucionar problemas, possibilitando a adequação de estratégias educacionais para rever a organização entre ensino e pesquisa ${ }^{5}$.

Paulo Freire ${ }^{1}$ afirma que é uma pena que 0 caráter socializante da escola, o que há de informal na experiência que se vivenela, de formação ou deformação, seja negligenciado. Fala-se quase exclusivamente do ensino de conteúdos, ensino lamentavelmente quase sempre entendido como transferência de saber. Afirma que qualquer progresso científico e tecnológico que não responde fundamentalmente aos interesses humanos eàs necessidades de nossa existência perdem sua significação. Desta forma, a todo avanço tecnológico haveria de corresponder o empe nho real de resposta imediata a qualquer desafio que pusesse em risco a alegria de viver dos homens e das mulheres.

É com a perspectiva problematizadora que desenvolvemos 0 estágio extramuros da FORPUSP em seu projeto Huka-Katu. N ele, tem-se como premissa que a educação pode ser vista como um instrumento de transformação social, desenvolvida não só através da educação formal, mas também por toda ação educativa que propicie a reformulação de hábitos, aceitação de novos valores e que estimule a criatividade.

Neste contexto, tem-se que a problematização deve ser pensada como um processo capaz de desenvolver a consciência crítica das causas reais de seus problemas e, ao mesmo tempo, criar uma prontidão para atuar no sentido de mudança ${ }^{6}$.

É importante que o processo educativo passe a ser pensado como um processo social, cultural eindividual, e para que ocorram mudanças comportamentais nesta direção, énecessário criar ou mudar percepções, utilizar forças motivadoras e tomar decisões para agir. Credita-se a este processo a possibilidade da aquisição de conhecimentos (o saber técnico e tecnológico que pode operar ações), habilidades (que levam ao saber fazer) e valores (crenças) e atitudes (avaliação positivas ou negativas, sentimentos etécnicas) se darem por meio da socialização.

Esta possibilidade coloca em pauta a aceitação e respeito à diferença, sem o que a escuta não se pode dar. Se discrimino a menina pobre ou menino negro, o menino índio, a menina rica; se discrimino a mulher, a camponesa, a operária, não posso evidentemente escutá-las e se não as escuto, não posso falar com eles, mas a eles, de cima para baixo. Sobretudo, me proíbo entendê los. Semesinto superior ao diferente, não importa quem seja, recuso-meescutá-lo ou escutá-la. 0 
diferente não é o outro a merecer respeito, é um isto ou aquilo destratável ou desprezível. Se a estrutura do meu pensamento é a única certa, irrepreensível, não posso escutar quem pensa e elabora seu discurso de outra maneira que não a minha, nem tampouco escuto quem fala ou escreve fora dos padrões de gramática dominante'.

Outra questão extremamente importante, e que deve ser considerada para atual proposição no processo de ensino-aprendizagem em carreiras na área da saúde, diz respeito ao contexto da nossa política oficial de saúdeeeducação. Salientamos que, em 1988, o texto constitucional brasileiro consagrou a saúde como produto social, e, com as Leis Orgânicas da Saúde (Leis 8.080 e 8.142) em 1990 foram estabelecidas bases para a organização e o funcionamento do Sistema Ú nico de Saúde (SUS), o que trouxe a possibilidade devivenciarmosum sistema que assegurasse acesso universal às ações e aos serviços de promoção, proteção, manutenção erecuperação da saúde da nossa população, bem como avaliar a satisfação desta com os serviços ofertados?.

É com baseno papel orientador na formação de profissionais na área da saúde para o contexto do SUS que a integralidade, o trabalho em equipe, a orientação comunitária, a ética, estética, etiqueta ea humanização estão sendo discutidos e vivenciados, visto que ações de saúde, tanto as de manutenção, promoção quanto as de recuperação, visam propiciar aos grupos humanos o mais alto grau de saúde, bem como permitir uma melhor qualidade de vida $a^{8-10}$.

Tendo em vista as considerações postas, o presente artigo procura contribuir para o debate acerca da necessidade de reconfiguração do processo de ensino-aprendizagem na formação de trabal hadores de saúde, em específico de cirurgiões-dentistas, por meio da descrição da teleodontologia no processo preparatório do estágio optativo "Projeto Huka-Katu - a FORP-USP no Xingu", que trabalha aspectos da formação, na dimensão cognitiva, considerando o contexto de sua aplicação, colaborando assim com as transformações que se processam no mundo contemporâneo, exigindo que a maneira de se conduzir o ensino e a prática de saúde bucal no país seja inovada, favorecendo o desenvolvimento das competências do cirurgião-dentista, para a atuação na atenção básica à saúde.
Formando profissionais da saúde para um novo modelo de atenção

Como já mencionado, a formação profissional voltada para necessidades sociais, no Brasil, vem se configurando, há alguns anos, em uma conjuntura peculiar, provocando reflexos profundos na educação, de um modo geral, e na formação superior em saúde, particularmente na construção de novas atividades que favoreçam o desenvolvimento de competências profissionais nos estudantes do curso de odontologia. Para tanto, a estratégia para formação profissional na atualidade se propõe levar o estudante a participar em novos cenários de ensino-aprendizagem, o que pode favorecer a reorientação do modelo formador de profissionais da área de saúde bucal.

Os novos cenários para a atenção em saúde consideram os model os de atenção ou modos de intervenção em saúde como sendo combinações tecnológicas estruturadas em função de problemas de saúde (danos e riscos) que compõem 0 perfil epidemiológico de uma dada população e queexpressam necessidades sociais de saúdehistoricamente definidas ${ }^{11}$.

Para a formação profissional em saúde, éfundamental reconhecer que a intervenção mais ampla realizada no Brasil, o Programa de Saúde da Família, juntamente com o processo de vigilância da saúde, tem por objetivo modificar 0 modelo de aten ção hegemônico, pois contempla os eixos reestruturantes do SU $S^{3,12-15}$.

A vigilância da saúde, de acordo com a sua proposta original, se apoia nas ações intersetoriais e procura reorganizar as práticas de saúde no âmbito local ${ }^{13}$. No projeto em questão, estemodo de intervenção em saúde pode ser considerado um eixo estruturante da maneira de agir em saúde. N ele, os problemas de saúde passam a ser analisados eenfrentados de forma integrada, por setores que historicamente têm trabalhado de maneira dicotomizada. Esse novo olhar sobre a saúde leva em consideração os múltiplos fatores envolvidos na gênese, no desenvolvimento e na percepção dos problemas: os determinantes sociais, os riscos ambientais, epidemiológicos e sanitários associados e os seus desdobramentos, no processo saúde-doença ${ }^{16}$.

Para esta concepção no campo da saúde, o objeto não é a cura, ou a promoção e proteção da saúde, mas a produção do cuidado, por meio do qual secrêquepoderá atingir a cura ea saúde, que é de fato a finalidade a que se quer chegar ${ }^{17}$. Para tanto, é no plano pedagógico que se testemunha a organização e a legitimação da passa- 
gem de um ensino centrado em saberes disciplinares a um ensino definido pela produção de competências em situações concretas e específicas. Essas competências são definidas em relação aos processos de trabalho que os sujeitos deverão ser capazes de compreender e dominar ${ }^{18}$, mobilizando recursos de diferentesnaturezas (conhecimentos, habilidades e atitudes).

Prova disto são as antigas e novas áreas de conhecimento que surgem sem admitir "enquadramento" em nenhuma das divisões oferecidas pelo antigo currículo, e, sendo esteum pensamento complexo, avança para além dos limites disciplinares. $\mathrm{O}$ estudo de $\mathrm{M}$ aia ${ }^{19}$ sobre temas transversais na formação como integradores das várias áreas do conhecimento suscita vários pontos de reflexão, com os quais nos identificamos: em que "lugar" se ensina eaprendea ética? Qual "disciplina" será a responsável pela formação humanística do profissional em saúde? E o mesmo pode ser pensado a respeito das capacidades de comunicação, liderança, resolutividade, entre outras.

Ao trazer este estudo, faz-se necessário pensar nos conceitos de campo e núcleo de competência e responsabilidade ${ }^{20}$, sendo que os saberes e responsabilidades comuns ou confluentes a várias profissões ou especialidades seriam conferidos ao campo de saber das profissões de saúde; já os núcleos do saber seriam entendidos como conjunto de saberes e responsabilidades específicos a cada profissão ou especialidade. N este sentido, as competências para o cirurgiãodentista passariam pelo aprendizado do campo e do núcleo de competências e responsabilidades, construindo, além de saberes, habilidades e atitudes próprias a esteprofissional, temas transversais que sustentariam sua prática enquanto trabalhador da área da saúde.

Os estágios, entendidos também como atividades extramuros, são os espaços que melhor possibilitam aos estudantes a construção das sínteses necessárias em torno de um desafio ${ }^{21}$. Assim, grandes desafios no processo ensino-aprendizagem podem ser superados por meio da aplicação de diferentes espaços de aprendizado, bem como a exploração de novas formas de parcerias entreas instituições deensino ediferentes setores da sociedade.

Por comprovação, temos o currículo oculto ou "currículo paralelo", em que se situam as atividades que o estudante busca espontaneamente no âmbito da própria instituição, como o caso de estágios em serviços e laboratórios, e o currículo informal, construído nas experiências de formação procuradas pelo estudante fora da ins- tituição, que são de grande valia nesta atual dinâmica de ensino-aprendizagem. Estes fatores permitem que os estudantes busquem, fora de seu currículo escolar, outros conhecimentos e saberes. Assim, ao buscar tais saberes na literatura e em outras linguagens e formas de comunicação, promove-se a inter e transdisciplinaridade proposta pela pedagogia freiriana ${ }^{5}$.

Em síntese, as alterações produzidas por esta outra lógica, que foge ao modelo fragmentado atual, resultam em deslocamentos denoções: dos saberes disciplinares à competência, na esfera educativa, e da qualificação à competência, na esfera do trabalho ${ }^{22}$.

0 que entendemos por competência, na estrutura curricular discutida até o presente momento? A legislação internacional classifica competências fundamentalmenteem básicas, genéricas e específicas. Formuladas pela Organização Internacional do Trabalho (OIT), as competências básicas são aquelas resultantes do processo de escolarização. As competências genéricas se referem ao comportamento profissional próprio do desempenho em diferentes setores ou atividades e são usualmente relacionadas à integração com tecnologias mais gerais. As competências específicas são aquelas diretamente relacionadas ao exercício de ocupações concretas, não sendo facilmente transferíveis de um a outro ambiente profissional ${ }^{23}$.

Já competência concebida por competência social ${ }^{24}$ refere-se ao saber que deve articular 0 saber-fazer, o saber-conviver e o saber-aprender. Assim, compreendemos que a construção de competência significa estabel ecer diretrizes deresponsabilidade do profissional baseadas em conhecimentos, habilidades eatitudes que, mobilizadas de forma complementar com as de outros profissionais, contribuirão para reorientar o processo de trabalho e construir novas práticas sociais, inclusive no campo da atenção básica em odontologia, na implementação do SUS.

No presente artigo, as competências a serem desenvolvidas pelos estudantes no estágio estão diretamenterelacionadas à futura prática na atenção básica à saúde e podem ser apresentadas sob duas óticas; a primeira, aquela que transfere na esfera do trabalho, da qualificação à competência, e a segunda, na esfera da educação, que desloca as noções dos saberes à competência. Estamos embasados principal mente na competência moral, que é definida como a capacidade para tomar decisões e el aborar juízos morais e agir de acordo com tais juízos ${ }^{25}$. É importante ressaltar que o presente artigo opta pela nomenclatura 
atenção básica à saúde, visto que, dentro de suas premissas e singularidades nacional, este termo dialoga em contexto mundial com a nomenclatura atenção primária à saúde ${ }^{15,26}$.

A concepção de competência adotada não se reduz à execução de tarefas e atividades relacionadas ao trabalho na dimensão técnico-instrumental, mas propõe a noção de competência humana do cuidado, em sua dimensão ética. Consideramos a competência profissional como um ato de assumir responsabilidades frente a situações detrabalho complexas; mas, antes de ser um conjunto de conhecimentos profissionais, a competência é uma atitude social. Por tratar-se de profissionais que atuam na área da saúde, a competência humana "[...] se expressa fundamental mente na capacidade de um ser humano cuidar do outro, de colocar em ação os conhecimentos necessários para prevenir eresolver problemas de saúde, mobilizando e disponibilizando tecnologias para 0 ato de cuidar" 26 .

Lembramos ainda que devemos nos voltar aos valores morais no intuito de desenvolver habilidades para que os mesmos sejam aplicados na tomada de decisões concretas ena ética ${ }^{27}$. Ainda, um sistema de certificação profissional baseado em competências deve compreender a competência em termos gerais como a aquela humana em "saber humanizar o conhecimento para que este possa servir aos fins éticos da história e não descambe em mera instrumentação decompetitividade" 28 .

Em síntese, para pensar a competência humana como pano de fundo de onde se desdobram todas as demais competências, énecessário compreendêla como um conceito político-educacional abrangente, como um processo de articulação e mobilização gradual e contínua de conhecimentos gerais e específicos, de habilidades teóricas e práticas, de hábitos eatitudes e devalores éticos, que possibiliteao indivíduo o exercício eficiente de seu trabalho, a participação ativa, consciente e crítica no mundo do trabal ho e na esfera social, além desua efetiva autorrealização ${ }^{24}$.

Ao abordar o conceito estético, presente no estágio, não nos referimos apenas ao aspecto da beleza proporcionada aos beneficiários de materiais restauradores, mas também ao ato de realizar arte e desenvolver criatividade para a motivação e educação em saúde bucal em comunidades de diferentes culturas.

Trabalhamos a estética como a arte na manifestação comunicativa, através dos instrumentos queutilizamos, por ser capaz deconduzir no estudante a transformação de suas convicções, o que também é uma das tarefas essenciais da escola, como centro de produção sistemática de conhecimento, trabalhando de forma crítica e inteligível as coisas e os fatos e a sua comunicabilidade ${ }^{1}$.

Quando nos referimos à etiqueta, cabe aqui esclarecermos o termo "etiqueta" como comportamento humano, em que os estudantes devem ser preparados para conviver em diferentes culturas, demonstrando capacidade deaceitar erespeitar o diferentee, ao fazer isto, atuar de maneira respeitosa e humana: "[...] para educar os jovens em valores emergentes, os métodos a serem usados deverão utilizar mais o diálogo, a escuta, a solidariedade e a criatividade" 29 .

Desta forma, consideramos que 0 ato de cuidar conjuga todos os saberes e práticas implicadas com sua construção e conformam os modelos deatenção à saúde. Concluímos que o estudo decompetências remexecom valoreséticosecom a formação do profissional. Contudo, não foi objeto deste trabalho o aprofundamento das competências em nível de compromisso rigoroso com a reorganização curricular vigente no campo da saúde.

\section{Aspectos cognitivos \\ para a experiência extramuro}

Com o intuito de se integrar à Política Nacional deSaúde Bucal eà Política Nacional de Atenção à Saúde dos Povos Indígenas, bem como desenvolver habilidades, atitudes econhecimentos pertinentes à busca por soluções dos problemas de interesse das comunidades em que atua a Faculdade de Odontologia de Ribeirão Preto da Universidade de São Paulo, em parceria com a Universidade Federal de São Paulo e o M inistério da Saúde (FUNASA), o estágio voluntário acadêmico denominado "Projeto Huka-Katu - a FORPUSP no Xingu" trabalha diferentes conceitos da saúde bucal e da promoção da saúde ${ }^{16,30}$.

No seu aspecto acadêmico, o estágio segue princípios definidos nas diretrizes curriculares para a educação dos profissionais de saúde do século $X X I$, de forma que todos os acadêmicos desenvolvam competências (conhecimentos, habilidades e atitudes) que possibilitem a sua interação e atuação multiprofissional, tendo como beneficiados os indivíduos e a comunidade, promovendo saúde para todos ${ }^{31}$.

É importante ressaltar que a não obrigatoriedade do estágio acaba por selecionar estudantes com perfil para trabalho em equipes compromissadas com a saúde coletiva e que buscam 
novos conteúdos e conhecimentos presentes em diversas culturas.

De forma objetiva, trata-se de uma atividade acadêmica, fora do ambiente acadêmico formal, ou seja, salas de aulas, laboratórios clínicos dentro do espaço universitário, onde [...] os alunos são levados atéa realidadedaquela população, aproximando- osao contexto sociocultural, o quepermite a modificação da visão mecanicista e reducionista da natureza humana. Esta experiência prática de ensino-aprendizagem permite uma ampliação do referencial social e cultural do processo saúde-doença e suas implicações na prática odontológica ${ }^{30}$.

Como umas das etapas de preparação dos estudantes da FORP-USP, antes de se depararem com a realidade de saúde nas aldeias indígenas, os estudantes utilizam novas ferramentas que auxiliam a disseminação do conhecimento, o que leva a uma mel hor compreensão dos problemas, gerando possibilidades de soluções mais adequadas ao novo contexto em que irão atuar e, consequentemente, melhora a qualidade das ações, que todavia serão sempre complementares à atuação humana. Uma das ferramentas utilizadas é a ferramenta digital (Ciber-tutor), que disponibiliza dois cursos, de forma que todos os estagiários tenham acesso à produção presente na literatura (saúde bucal coletiva ecultura indígena).

Este instrumento auxiliar de acesso dos estudantes propicia maior potencialização ao aprendizado teórico/cognitivo, havendo, assim, maior interação no tempo e no espaço e está presente na teleodontologia, queà semelhança da telemedicina, envolve o saber e a arte em saúde como um meio de comunicação (Internet) que possa unir dois ou mais pontos distantes fisicamente. Estas ferramentas são tecnologias de telecomunicação e de informaç̧ão que suportam serviços, treinamento e informação em saúde ${ }^{32}$.

Sendo uma ferramenta complementar ao ensino da odontologia, possui requisitos pedagógicos e contribui como uma plataforma de educação ${ }^{33}$, constituindo-se em uma tecnologia para o aprimoramento do ensino.

A teleodontologia como meio auxiliar eletrônico contribui para a formação do futuro cirurgião-dentista, propiciando a análise crítica e reflexiva nos diferentes níveis de aten ção à saúde ${ }^{34}$. Podemos afirmar que se trata de um instrumento eletrônico, tecnologia leve-dura, na qual estão presentes a informação e o conteúdo discutido, bem como o método de abordagem dos estudantes, valorizando a escuta e o vínculo. Assim, ao permitir a interação do estudante com outras dimensões de seu aprendizado, não apenas o co- nhecimento técnico, este instrumento possibilita uma associação de tecnologias na construção do processo ensino-aprendizagem, em que podemos dizer que o uso de diferentes tecnologias auxilia na construção do conhecimento.

$\mathrm{Na}$ atualidade, o complexo processo de ensinar e aprender envolve diferentes recursos tecnológicos e pedagógicos, devendo também ser desenvolvido em nível social, ou seja, acompanhado de experiências e vivências em sociedade. 0 pensamento pedagógico "freiriano" real çatambém a dimensão do aprendizado como um processo de transformação cultural. A educação é muito mais que instrução, sendo um longo processo enraizado em uma consciência histórica. Por isto, aprende-se quando se quer aprender e só se aprende o queésignificativo. N este contexto, acreditamos que a escola e/ou universidade deve ser constituída de múltiplos espaços de formação, exercendo uma função mais formativa e menos informativa. D eve ser composta por "círculos de cultura" dentro e fora das suas fronteiras, muito mais gestora do conhecimento social do que lecionadora9. Por isto, é importante fundamentar no seu interior o ensino-aprendizagem em ambientes interativos, através, por exemplo, do uso de recursos como a teleodontologia.

Ao abordar um novo contexto de ensinoaprendizagem, se faz necessária a compreensão mais eficaz, no sentido dese buscar procedimentos úteis e realizáveis, entre estudantes-ensinodocentes, para um aprendizado condizente com a realidade social.

Envolvidos pelo panorama exposto, no presente artigo, apresentamos dois módulos teóri$\cos ^{35}$ de ampla abordagem em sociologia, antropologia, saúde coletiva, políticas públicas eodontologia preventiva, os quais foram apresentados aos estudantes tendo a Internet como elemento de acesso. Estes módulos, entendidos como pré requisito, são aplicados aos estudantes que ingressam como voluntários no projeto (estágio) extramuro Huka-Katu ${ }^{30}$.

M ais objetivamente, os estudantes, em tempo e local estabelecidos por eles próprios, acessam a Internet e realizam a leitura eo estudo dos tópicos expostos. No final de cada tópico, perguntas devem ser respondidas de forma adequada para que passem para os tópicos seguintes. Tal metodologia estimulou o interesse e a curiosidade em superar as barreiras para se atingir os próximos assuntos a serem abordados. A sequência apresentada dos assuntos foi disposta para que se estabelecesse uma dinâmica. Abordando inicialmente aspectos humanos, sociais, culturais 
ehistóricos eposteriormente políticos etécnicos, este material não distanciou a relação interpessoal com os responsáveis pelo projeto, visto que dúvidas, argumentações e novas informações eram discutidas com os estudantes em momentos de concentração presenciais, após a aplicação destes módulos.

O primeiro módulo apresentado aos alunos foi dividido em oito tópicos (Quadro 1), contendo uma sequência de 43 questões de múltipla escolha. Preocupou-se em mostrar inicialmente a relevância de assuntos como a relação do homem em sociedade, diferentes culturas e o contato social. Assim, passou-se para o estudo de raças no Brasil, bem como conceitos de cidadania epolítica.

A partir destemomento, em que o estudante já havia tido um contato com tais perspectivas, abordou-se os conceitos de saúde- doença e políticas de saúde. N este tópico, introduziu-se ao estudante um panorama do sistema de saúde para que o mesmo pudesse se familiarizar com a saúde pública brasileira, estudando o Sistema Ú nico de Saúde, atenção básica em saúde e humanização da saúde no Brasil. Com esta base de estudos, os estudantes, ao darem sequência em seus tópicos, abordavam no final do M ódulo I os conceitos da saúde indígena, bem como a saúde bucal do referido povo brasileiro. Assim, conseguiuse a sensibilização destes estudantes ao interesse em sociologia, antropologia, promoção de saúde e políticas públicas.

O segundo módulo apresentado aos estudantes foi dividido em seis tópicos (Quadro 2), conten do uma sequência de 38 questões de múltipla escolha. Por se tratar de um momento no qual os estudantesjá haviam inicialmente trabaIhado questões da antropologia, sociologia e o contato teórico inicial com a cultura indígena do Xingu, o segundo módulo concentrou-seem uma sequência mais histórica da saúde pública no Brasil e políticas de saúde bucal, procedimentos em atenção básica em saúde bucal, bem como as políticas deatenção a saúde indígena. Assim, resgatou-se uma visão mais aprofundada do Sistema Ú nico de Saúdee, neste contexto, a atenção e a assistência à saúde bucal indígena foram trabalhadas em vários aspectos.

Como se tratou de um módulo teórico para preparação dos estudantes para o estágio extramuro em aldeias indígenas, foram trabalhados os procedimentos, as competências e as atividades odontológicas a serem realizadas, que foram embasadas nos procedimentos previstos para a equipe da aten ção básica em saúde. A relevância
Quadro 1. Esquema do M ódulo I.

Teleodontologia, Projeto Huka-Katu - a FORP-

USP no Parque Indígena do Xingu. Ribeirão Preto, $2006^{35}$.

\begin{tabular}{|l|}
\hline Módulo I \\
\hline Tópico 1: Sociedades e sociologia aplicada \\
Nenhum homem é uma ilha
\end{tabular}

Agir e interagir na sociedade - o ser social

Contato social

Cultura nas diferentes sociedades

Processos culturais

Controle social

Sociedades, culturas, globalização e neoliberalismo

Tópico 2: Do homo sapiens à "humanização"

0 conceito de raça aplicada à espécie humana

A variabilidade da espécie humana

Os troncos raciais no Brasil

Tópico 3: Cidadania e política

Política?

Cidadania?

Tópico 4: Saúde e doença: práxis social

0 que é saúde?

O processo saúde-doença

Promoção de saúde

A promoção de saúde como movimento social

Tópico 5: Políticas de saúde pública

Políticas sociais

Políticas públicas

O Sistema Ú nico de Saúde (SUS)

Atenção básica à saúde

Política nacional de saúde bucal

Tópico 6: Humanização serviços de saúde

Relações interpessoais

Acolhimento e acesso

H umanização dos serviços de saúde (SUS)

Tópico 7: Saúde indígena

A população indígena no Brasil

U m breve histórico sobre indigenismo

A política de saúde indígena

Distritos sanitários especiais indígenas (DSEIS)

O subsistema de saúde indígena no DSEI/Xingu

Tópico 8: Saúde bucal indígena

Atenção à saúde bucal indígena

Contextualização da cultura indígena no Xingu

Controle social na cultura indígena

Levantamentos em saúde bucal indígena

do M ódulo II esteve associada à sensibilização dos estudantes para trabalhar em equipe, vivenciar a real promoção de saúde, estudar políticas públicas e a política nacional de saúde bucal. 


\section{Colaboradores}

W M estriner Jr., SF M estriner, AF Bulgarelli eSM M ishima participaram da concepção teórica, construção metodológica, redação e pesquisa, bem como da revisão textual final.

\section{Referências}

1. Freire PRN. Professora sim, tia não: cartas a quem ousa ensinar. São Paulo: Olho D’Água; 1993.

2. Nuto SAS, Noro LRA, Cavalsina PG, Costa ICC, Oliveira AGR. 0 processo ensino-aprendizagem e suas consequências na relação professor-alunopaciente. Cien Saude Colet 2006; 11(1):89-96.

3. Mendes EV. A reforma sanitária e a educação odontológica. Cad Saude Publica 1986; 2(4):533-552.

4. Souza ECF. Bucalidade: conceito-ferramenta de religação entre clínica e saúde bucal coletiva. Cien Saude Colet 2006; 11(1):24-28.

5. Gadotti M. 0 plantador do futuro. Viver M ente \& Cérebro 2005; (4):8-15.

6. Ioshida LC. M etodologias problematizadoras no ensino em saúde. In: Batista NA, Batista SH, organizadores. Docência em saúde: temas e experiências. São Paulo: Senac; 2004.

7. Brasil. Ministério da Saúde. CONASEM S. Legislação básica do SUS. Brasília: Ministério da Saúde; 1999.

8. Brasil. M inistério da Saúde. Secretaria de Atenção à Saúde. Núcleo Técnico da Política Nacional de Humanização. Ambiência. 2ª ed. Brasília: Ministério da Saúde; 2006.

9. Brasil. M inistério da Saúde. Secretaria de Atenção à Saúde. Núcleo Técnico da Política Nacional de Humanização. A colhimento nas práticas de produção de saúde. 2a ed. Brasília: Ministério da Saúde; 2006.

10. Brasil. M inistério da Saúde. Secretaria de Atenção à Saúde. Núcleo Técnico da Política Nacional de Humanização. Grupo de Trabalho de Humanização. 2a ed. Brasília M inistério da Saúde; 2006.

11. Paim JS. Modelos de Atenção e Vigilância da Saúde. In: Rouquayrol MZ, Almeida Filho N, organizadores. Epidemiologia \& Saúde. Rio de Janeiro: Medsi; 2003. p. 567-586.

12. Campos CEA. O desafio da integralidade segundo as perspectivas da vigilância da saúde e da saúde da família. Cien Saude Colet [periódico na Internet] 2003 [acessado 2007 jan 21]; 8(2):[cerca de 16 p.]. Disponível em: http://www.scielo.br/pdf/csc/v8n2/ a18v08n2.pdf

13. Paim JS. Atenção à saúde no Brasil. In: Brasil. Ministério da Saúde. Saúde no Brasil - Contribuições para a Agenda de Prioridades de Pesquisa. Brasília: M inistério da Saúde; 2004. p. 15-40.

14. Mendes EV. Uma agenda para a saúde. São Paulo: Hucitec; 1996.

15. Sousa M F, Hamann EM. Programa Saúde da Família no Brasil: uma agenda incompleta? Cien Saude Colet [periódico na Internet] 2007 [acessado 2009 mar 10];[cerca de 12 p.]. Disponível em: http:// www.scielosp.org/pdf/csc/v14s1/a02v14s1.pdf

16. Lemos PN, Hirooka LB, N unes SAC, Arantes R, Mestriner SF, M estriner Jr. W. O Modelo de atenção à saúde bucal no M édio e Baixo Xingu: parcerias, processos e perspectivas. Cien Saude Colet [periódico na Internet] 2007 [acessado 2009 mar 18];[cerca de 5 p.]. Disponível em: http://www.scielosp.org/ $\mathrm{pdf} / \mathrm{csc} / \mathrm{v15s} 1 / 056 . \mathrm{pdf}$

17. Merhy EE, Magalhães Jr. HM, Rimoli J, Franco TB, Bueno WS, organizadores. 0 trabalho em saúde: ol hando e experienciando o SUS no cotidiano. São Paulo: Hucitec; 2004. 
18. Gontijo LPT. Construindo as competências do cirurgião-dentista na atenção primária em saúde [tese]. Ribeirão Preto (SP): Escola de Enfermagem de Ribeirão Preto, Universidade de São Paulo; 2007.

19. Maia JA. O currículo no ensino superior em saúde. In: Batista NA, Batista SH, organizadores. Docência em saúde: temas e experiências. São Paulo: Senac; 2004.

20. Campos GWS. Reforma da reforma: repensando a saúde. São Paulo: Hucitec; 1997.

21. Fagundes NC, Burnham TF. Discutindo a relação entre espaços e aprendizagem na formação de profissionais de saúde. Interface (Botucatu) 2005; 9(16):105-114.

22. Desaulniers JBR. Formação, competência, cidadania. Educ. Soc. 1997; 18(60):51-63.

23. Conselho Internacional de Enfermeiras. ICN Framework of Competencies for the Generalist Nurse. Ge neva: Conselho Internacional de Enfermeiras; 2003.

24. Deluiz N. Formação do trabalhador: produtividade e cidadania. Rio de Janeiro: Shape; 1995.

25. Kohlberg $L$. The philosophy of moral development moral stages and the idea of justice. New York: Harper \& Row; 1986.

26. Deluiz N. O modelo das competências profissionais no mundo do trabalho e na educação: implicações para o currículo. Boletim Técnico do SENAC 2001; 27(3):12-25.

27. Lind $G$. The meaning and the measurement of moral judgment competence, a dual aspect of theory. In: Fasko D, Willis W, editors. Contemporary philosophical and psychological perspectives on moral development and education. Creskill: Hampton Press; 2002.

28. Demo P. Educação profissional: desafio da competência humana para trabalhar. In: Educação profissional: 0 debate da(s) competência(s). Brasília: M inistério do Trabalho/SEFOR; 1997.

29. De Masi D. 0 ócio criativo. Rio de Janeiro: Sextante; 2001.

30. Oliveira C, Pacagnella RC, M attos MC, Bregagnolo JC, Watanabe M GC, M estriner Jr. W. Projeto HukaKatu: a FORP-USP no Parque Indígena no Xingu. Revista da ABENO 2005; 5(2):135-139.

31. Brasil. Lei de diretrizes e bases da educação nacional. Brasília: Art-Graf; 1996.

32. Lopes PRL, Barsottini CN, Pisa IT, Sigulem D . 0 que é Telemedicina?[site da Internet] 2005 [acessado 2007 nov 23]. Disponível em: http://www.unifesp.br/dis/ set/telemedicina.php

33. Pardini LC. Teleodontologia: É preciso divulgar. [site da Internet] 2006 [acessado 2006 nov 22]. Disponível em: http://podae.forp.usp.br/

34. Semprini M. Teleodontologia: Objetivo. [site da Internet] 2006 [acessado 2006 ago 19]. Disponível em: http://podae.forp.usp.br/

35. M estriner Jr. W. Projeto Xingu: Huka-Katu. [site da Internet] [acessado 2008 mai 10]. Disponível em: http://podae.forp.usp.br/index.php?option =com content\&task=view\&id $=144 \&$ Itemid $=18$ 